\title{
KORELASI IMT (INDEKS MASSA TUBUH) DENGAN KEJADIAN FLUOR ALBUS PADA REMAJA
}

\author{
Correlation Of Bmi (Body Mass Index) With The Even Of Albus Fluor In \\ Adolescents
}

Eka Fitriyanti ${ }^{1}$

Universitas 'Aisyiyah Yogyakarta

(ekamifka@gmail.com)

\begin{abstract}
ABSTRAK
Latar Belakang : Fluor albus dapat menimbulkan beberapa komplikasi seperti terjadinya infeksi pada saluran berkemih dan abses kelenjar bartholin, Fluor albus yang tidak ditangani dengan baik maka akan menimbulkan infeksi yang menyebar ke atas atau ke organ reproduksi seperti endometrium, tuba fallopi, dan serviks menyebabkan terjadinya penyakit inflamasi pada panggul (PID) yang sering menimbulkan infertilitas dan perlengketan saluran tuba yang memicu terjadinya kehamilan ektopik. Overweight dan obesitas pada awal/ dewasa meningkatkan resiko terjadinya gangguan menstruasi, hipertensi pada kehamilan dan subfertilitas. BMI pada masa anak memiliki pengaruh yang cukup kuat dalam kesehatan reproduksi seorang perempuan di masa depannya.

Tujuan : Penelitian ini bertujuan untuk mengetahui korelasi IMT dengan kejadian fluor albus pada remaja.

Metode : Responden pada penelitian ini adalah mahasiswa semester I prodi Kebidanan Jenjang Diploma IV Universitas 'Aisyiyah Yogyakarta. Desain penelitian yang digunakan pada penelitian ini adalah kuantitatif dengan cross sectional. Fluor Albus diukur melalui kuesioner. Dan korelasi IMT dengan Fluor Albus dianalisis menggunakan uji Spearman Rank.

Hasil : Hasil penelitian yang telah dilakukan menunjukkan bahwa dengan uji Spearman Rank menunjukkan tidak terdapat hubungan yang signifikan $(\mathrm{p}=0,829)$ antara IMT (Indeks Massa Tubuh) dengan kejadian fluor albus.

Simpulan: Saran untuk peneliti selanjutnya adalah perlu dilakukan lebih lanjut dengan jumlah sampel yang lebih besar serta lokasi cakupan penelitian yang lebih luas agar hasil penelitian lebih dapat digeneralisasikan
\end{abstract}

Kata kunci: IMT, Fluor Albus.

\section{ABSTRACT}

Background: Fluor albus can cause several complications such as infection in the urinary tract and abscess of the Bartholin gland, Fluor albus which is not handled properly will cause an infection that spreads upwards or to the reproductive organs such as the endometrium, fallopian tubes, and cervix causing inflammation of the pelvic disease (PID) which often causes infertility and adhesions of the fallopian tubes which triggers ectopic pregnancy. Early / adult 
overweight and obesity increase the risk of menstrual disorders, hypertension in pregnancy and subfertility. BMI during childhood has a strong influence on the reproductive health of a woman in her future

The Purpose : This study aims to determine the correlation of BMI with the incidence of fluor albus in adolescents.

Method: Respondents in this study were first semester students of midwifery study program at Diploma IV University level 'Aisyiyah Yogyakarta. The research design used in this study was quantitative with cross sectional. Fluor Albus is measured through a questionnaire. And the correlation of BMI with Fluor Albus was analyzed using the Spearman Rank test.

Result: The results of the research that have been conducted show that the Spearman Rank test shows that there is no significant relationship $(p=0.829)$ between BMI (Body Mass Index) and the incidence of fluor albus.

Conclusion: Suggestions for further researchers are to be carried out further with a larger sample size and a wider range of research locations so that research results can be more generalized.

Key words: BMI, fluor albus.

\section{PENDAHULUAN}

Fluor albus (keputihan, leukorea, vaginal discharge) merupakan istilah yang digunakan untuk cairan yang keluar dari genitalia wanita yang bukan berupa darah. Fluor albus adalah gejala yang sering ditemukan pada pasien ginekologi. Sepertiga pasien ginekologi datang dengan keluhan fluor albus. Fluor albus menjadi salah satu dari 25 alasan terbanyak untuk mengunjungi tenaga medis di Amerika Serikat.

Fluor albus beresiko pada remaja, karena pada masa ini remaja mengalami pubertas yang ditandai dengan datangnya mestruasi. Pada sebagian orang, saat menjelang menstruasi akan mengalami Fluor albus. Fluor albus ini normal selama jernih atau bening, tidak berbau, tidak terasa gatal dan dalam jumlah yang tidak berlebihan. Bila cairan berubah menjadi berwarna kuning, berbau dan disertai rasa gatal maka telah terjadi Fluor albus yang patologis (Pribakti, 2010).

Fluor albus dapat menimbulkan beberapa komplikasi seperti terjadinya infeksi pada saluran berkemih dan abses kelenjar bartholin, Jika seorang remaja nantinya menikah dan menjadi ibu hamil serta masih mengalami fluor albus sebagai akibat dari infeksi trikomonas dapat mengakibatkan kelahiran prematur, Fluor albus yang tidak ditangani dengan baik maka akan menimbulkan infeksi yang menyebar ke atas atau ke organ reproduksi seperti endometrium, tuba fallopi, dan serviks menyebabkan terjadinya penyakit inflamasi pada panggul (PID) yang sering menimbulkan infertilitas dan perlengketan saluran tuba yang memicu terjadinya kehamilan ektopik (Rabiu et al., 2010)

Sekitar $70 \%$ remaja putri di Indonesia mengalami masalah Fluor albus, disamping dari karena kondisi cuaca yang lembab sebagai penyebab infeksi jamur, masalah Fluor albus sendiri bisa disebabkan dari pola makan yang tidak benar pada remaja sehingga banyak remaja yang mengalami kegemukan. 
Kegemukan dapat membuat kedua paha tertutup rapat sehingga mengganggu sirkulasi udara dan meningkatkan kelembaban sekitar vagina (Army, 2007).

Menurut data penelitian tentang kesehatan reproduksi menyatakan bahwa 75\% wanita di dunia pernah mengalami fluor albus paling tidak sekali dalam hidup dan 45\% diantaranya mengalami fluor albus 2 kali atau lebih. Di Indonesia, terdapat peningkatan angka kejadian fluor albus pada remaja. Pada tahun 2002, 50\% remaja di Indonesia pernah mengalami fluor albus.Tahun 2003 angka tersebut naik menjadi 60\% dan tahun 2004 menjadi 70\% (Persia,2015).

Overweight dan obesitas pada awal dewasa meningkatkan resiko terjadinya gangguan menstruasi, hipertensi pada kehamilan dan subfertilitas. BMI pada masa anak memiliki pengaruh yang cukup kuat dalam kesehatan reproduksi seorang perempuan di masa depannya (Lake dalam Aldini, 2012)

Berdasarkan latar belakang diatas, maka peneliti merasa perlu melakukan penelitian tentang "Korelasi IMT (Indeks Massa Tubuh) dengan fluor albus pada Remaja."

\section{METODE PENELITIAN}

Jenis penelitian yang digunakan adalah penelitian analitik yang digunakan untuk mengukur hubungan (korelasi) IMT (Indeks Massa Tubuh) dengan fluor albus pada remaja. Rancangan penelitian ini menggunakan Cross Sectional. Rancangan Cross Sectional merupakan rancangan penelitian yang melakukan observasi atau pengukuran variabel pada saat tertentu. Variabel Bebas pada penelitian ini adalah IMT (Indeks Massa Tubuh) dan variabel terikat pada penelitian ini adalah Kejadian Fluor Albus.

Populasi dalam penelitian ini adalah semua mahasiswi remaja putri usia 1721 tahun semester I di Prodi DIV Kebidanan Universitas Aisyiyah Yogyakarta yaitu berjumlah 152 orang. Sampel dalam penelitian ini adalah semua remaja putri yang memenuhi kriteria tertentu. Pengambilan sampel penelitian ini menggunakan Simple Random Sampling. Sampel dalam penelitian ini berjumlah 98 responden dimana semua responden adalah mahasiswi semester 2 Prodi Kebidanan jenjang Diploma IV Universitas 'Aisyiyah Yogyakarta.

Analisa data merupakan suatu proses penyederhanaan data ke dalam bentuk yang mudah dibaca dan diinterpretasikan melalui proses analisis. Penelitian ini menggunakan uji statistik Spearman Rank dengan menggunakan taraf signifikan 0,05 , apabila nilai $\mathrm{p}<0,05$ maka Ha diterima dan Ho ditolak, artinya ada hubungan IMT (Indeks Massa Tubuh) dengan Fluor albus, sebaliknya apabila p>0,05 maka Ha ditolak dan Ho diterima artinya tidak ada hubungan IMT (Indeks Massa Tubuh) dengan Fluor albus. 


\section{HASIL DAN PEMBAHASAN}

Tabel 1 Distribusi Frekwensi Karakteristik Responden Berdasarkan Usia

\begin{tabular}{lccc}
\hline & Karakteristik & Frekwensi (f) & Prosentase (\%) \\
\hline 17 tahun & 7 & 7,1 \\
18 tahun & 67 & 68,4 \\
19 tahun & 21 & 21,4 \\
20 tahun & 20 & 3,1 \\
\hline Total & 98 & 100 \\
\hline
\end{tabular}

Berdasarkan Tabel 1. Responden dalam penelitian ini adalah mahasiswi Prodi Kebidanan Jenjang Diploma IV Universitas 'Aisyiyah Yogyakarta yang berjumlah 98 responden. Semua responden adalah berjenis kelamin perempuan. Mayoritas responden pada penelitian ini berusia 18 tahun yaitu sebesar 67 responden $(68,4 \%)$ dan sebagian lagi berusia 17 tahun berjumlah 7 responden $(7,1 \%), 19$ tahun sebanyak 21 responden $(21,4 \%)$ dan 20 tahun sebanyak 3 responden $(3,1 \%)$.

Tabel 2 Distribusi Frekuensi Variabel IMT Responden

\begin{tabular}{ccc}
\hline Pengetahuan & Frekuensi (f) & Prosentase (\%) \\
\hline Normal & 86 & 87,8 \\
Overweight & 12 & 12,2 \\
Obese & 0 & 0 \\
Total $(\mathrm{n})$ & 98 & 100 \\
\hline
\end{tabular}

Tabel 2 diatas menunjukkan bahwa Mayoritas IMT responden pada penelitian ini memiliki IMT yang normal yaitu berjumlah 86 responden $(87,8 \%)$, overweight sebanyak 12 responden $(12,2 \%)$ dan tidak ada responden yang mengalami obese $(0 \%)$. Sedangkan responden yang mengalami kejadian Fluor albus yang normal yaitu berjumlah 68 responden $(69,4 \%)$ dan sebagian kecil mengalami kejadian fluor albus yang patologis yaitu sebesar 30 responden $(30,6 \%)$.

Hasil uji Spearman Rank menunjukkan bahwa didapatkan nilai Sig. (p) 0,829 dengan taraf kesalahan $(\alpha)$ 0,05. Untuk menentukan hipotesis diterima atau tidak maka besarnya nilai signifikansi (p) dibandingkan dengan nilai kesalahan $(\alpha)$. Hasil uji statistik Spearman Rank menunjukkan nilai $\mathrm{p}>\alpha(0,829>0,05)$ sehingga hipotesis $\left(\mathrm{H}_{0}\right)$ diterima. Dengan demikian dapat disimpulkan bahwa tidak ada korelasi IMT dengan kejadian fluor albus.

The World Health Organization (WHO) pada tahun 1997, The National Institute of Health (NIH) pada tahun 1998 dan The Expert Committee on Clinical Guidelines for Overweight in Adolescent Preventive Services telah merekomendasikan Body Mass Index (BMI) atau Indeks Massa Tubuh (IMT) sebagai baku pengukuran obesitas pada anak dan remaja di atas usia 2 tahun. BMI merupakan petunjuk untuk menentukan kelebihan berat badan berdasarkan Indeks 
Quatelet (berat badan dalam kilogram dibagi dengan kuadrat tinggi badan dalam meter $\left(\mathrm{kg} / \mathrm{m}^{2}\right)$.

Ada dua klasifikasi yang digunakan untuk mengintrepertasikan IMT pada anak dan remaja. Metode pertama digunakan oleh the International Obesity Task Force, bekerjasama dengan the Global Prevention Alliance berfokus pada pencegahan obesitas pada anak, menggunakan pengukuran IMT seperti yang digunakan untuk orang dewasa dengan tiga kategori: normal ( IMT < 25), overweight (IMT $\geq 25<30$ ) dan obese (IMT $\geq 30$ ).

Keputihan dapat dibedakan menjadi dua jenis, yaitu keputihan normal (fisiologis) dan keputihan abnormal (patologis). Keputihan normal dapat terjadi pada masa menjelang dan sesudah menstruasi, pada sekitar fase sekresi antara hari ke 10-16 saat menstruasi, juga terjadi melalui rangsangan seksual. Keputihan abnormal dapat terjadi pada semua alat genitalia (infeksi bibir kemaluan, liang senggama, mulut rahim, rahim dan jaringan penyangga, dan pada infeksi penyakit hubungan seksual)(Manuaba, 2011).

Dari hasil uji statistik untuk membuktikan hipotesis adanya korelasi IMT dengan kejadian fluor albus menggunakan uji Spearman Rank menunjukkan bahwa didapatkan nilai Sig. (p) 0,829 dengan taraf kesalahan $(\alpha) 0,05$. Untuk menentukan hipotesis diterima atau tidak maka besarnya nilai signifikansi (p) dibandingkan dengan nilai kesalahan $(\alpha)$. Hasil uji statistik Spearman Rank menunjukkan nilai $\mathrm{p}>\alpha(0,829>0,05)$ sehingga hipotesis $\left(\mathrm{H}_{0}\right)$ diterima. Dengan demikian dapat disimpulkan bahwa tidak ada korelasi IMT dengan kejadian fluor albus.

Hal ini tidak sesuai dengan Army (2007) yang menyatakan bahwa Kegemukan dapat membuat kedua paha tertutup rapat sehingga mengganggu sirkulasi udara dan meningkatkan kelembaban sekitar vagina, sehingga secara tidak langsung kegemukan juga menjadi penyebab terjadinya fluor albus.

Faktor penyebab keputihan belum dapat diketahui secara pasti, akan tetapi keputihan merupakan gejala terjadinya suatu penyakit tertentu pada seorang wanita, salah satunya adalah karena infeksi (Manuaba, 2011).

Hal ini diperkuat dari penelitian yang dilakukan oleh Suhartami (2014) yang diperoleh data bahwa dari 28 responden yang melakukan personal hygiene secara negative terdapat 8 responden yang mengalami fluor albus fisiologis sebanyak 8 responden dan yang mengalami fluor albus patologis sebanyak 20 responden. Dari sebagian besar responden yang mengalami fluor albus patologis dikarenakan personal hygiene yang negative sehingga dari personal hygiene yang kurang tersebut dapat memicu berkembangnya bakteri sebagai penyebab terjadinya infeksi.

Personal hygiene yang kurang baik misalnya cara cebok yang salah dapat mengakibatkan terjadinya banyak hal, mulai dari infeksi saluran kemih, infeksi organ kewanitaan yang menimbulkan keluhan keputihan, bahkan dapat menjadi salah satu faktor resiko terjadinya kanker serviks.

Hasil pengambilan data dari mahasiswa DIV Kebidanan UNISA didapatkan dari 96 mahasiswa masih ada 11 mahasiswa yang melakukan personal hygiene yang kurang baik, diantara ny cara cebok yang salah, tidak menjaga 
kelembaban pasca buang air kecil ataupun tidak terlalu sering mengganti celana dalam dan pembalut ketika haid.

Penyebab fluor albus berlebihan terkait dengan cara kita merawat organ reproduksi. Salah satunya personal hygiene kurang tepat seperti misalnya cara cebok yang benar dari depan ke belakang untuk menghindari perpindahan bakteri dari dubur ke vagina, baik saat menyiram, membersihkan, maupun mengeringkan, penggunaan celana dalam yang baik, seberapa banyak harus ganti celana dalam. Sebagian remaja menganggap perilaku personal hygine seperti cara cebok merupakan hal sepeleh, padahal perilaku personal hygine sangat penting dan dilaksanakan dengan benar agar dapat terhindar dari berbagai penyakit yang disebabkan karena personal hygine yang tidak benar (Revina, 2014).

Dari hasil penelitian juga didapatkan bahwa dari 96 mahasiswi DIV Kebidanan UNISA masih ada 10 orang yang menggunakan pantyliner. Penggunaan pantyliner ini berlangsung sering bahkan setiap hari sejak mahasiswa mendapatkan menstruasi pertama kali.

Pemakaian panty liner juga merupakan salah satu faktor predisposisi timbulnya keputihan. Panty liner (pantliner, panty shield) merupakan salah satu jenis pembalut wanita yang digunakan pada saat diluar periode menstruasi. Panty liner memiliki susunan yang sama dengan pembalut ketika menstruasi namun ukurannya lebih tipis. Pemakaian panty liner bertujuan untuk menyerap cairan vagina, keringat, bercak darah, sisa darah menstruasi dan terkadang juga dipakai sebagai penyerap urin bagi wanita inkontinensia (Persia, 2015).

Dapat disimpulkan bahwa banyak faktor yang menjadi penyebab terjadinya Fluor albus, diantaranya adalah personal hygiene yang kurang baik, penggunaan pantyliner dan yang paling utama adalah infeksi yang terjadi pada seorang wanita. IMT tidak secara langsung menjadi penyebab terjadinya fluor albus.

\section{SIMPULAN DAN SARAN}

\section{Simpulan}

Berdasarkan hasil penelitian yang telah dilakukan disimpulkan bahwa uji Spearman Rank menunjukkan tidak terdapat hubungan yang signifikan $(\mathrm{p}=0,829)$ antara IMT (Indeks Massa Tubuh) dengan kejadian fluor albus.

\section{Saran}

Perlu dilakukan penelitian lebih lanjut dengan pembatasan kriteria faktor luar yang berpengaruh terhadap kejadian Fluor albus seperti faktor infeksi dan fistel di vagina termasuk juga dilakukan analisis terhadap variabel-variabel perancu lainnya selain yang disebutkan diatas, dengan harapan semakin memperkuat simpulan dan semakin memperkecil bias.

Pada seorang perempuan dapat diupayakan pencegahan kejadian fluor albus dengan tetap menjaga personal hygiene terutama vulva hygiene. 


\section{DFTAR PUSTAKA}

Ababa, M. 2003. Memahami Kesehatan Reproduksi pada Wanita. Jakarta :Ercon Aldini. 2012. Hubungan BMI dengan Resiko Kejadian Infertilitas pada Perempuan. Skripsi. Fakultas Kedokteran Universitas Sebelas Maret Surakarta.

Arikunto, S. 2006. Prosedur Penelitian Suatu Pendekatan Praktik. Jakarta: Rineka Cipta.

Army, Y. 2007. Media Sehat. Semarang: Arfamedia Group.

Daniels, Stephen et al. 1997. The Utility of BMI as a Measure of Body Fatnew in Children and Adolescents : Different by Race and Gender.PEDIATRICS Vol : 99 No.6 June 1997.

Demerath, Ellen et al. 2006. Do Charges in BMI Percentile Reflects Changes In Body Composition in Children? Data from the Fels Longitudinal Study. PEDIATRICS Vol. 117 No. 3 March 2006.

Katarini, dkk. 2009. Kesehatan Reproduksi Wanita. Jakarta : Trans Info Media.

Manuaba. 2009. Memahami Kesehatan Reproduksi Wanita. Jakarta : EGC.

Persia, A. 2015. Hubungan Pemakaian Panty Liner dengan Kejadian Fluor Albus pada Siswi SMA di Kota Padang berdasarkan wawancara terpimpin (kuesioner). Jurnal Kesehatan Andalas. http:// jurnal.fk.unand.ac.id

Pribakti, B. 2010. Tips \& Trick merawat Organ Intim. Jakarta: Sagung Seto.

Pudjiadi, Antonius et al. 2010.Pedoman pelayanan Medis IDAI. Jilid 1 : Jakarta : Pengurus Pusat IDAI

Rabiu et al. 2010. Female Reproductive Tract Infection : Understandings and Care Seeking Behaviour Among Women of Reproductive Age In Lagos, Nigeria, BMC Women's Health 10 (8).

Sastroasmoro, S dan Ismael, S. 2008. Dasar-dasar Metodologi Penelitian Klinis. Jakarta : Sagung Seto

Suhartami, M.A. 2015.Personal Hygiene dengan Kejadian Fluor Albus pada Santriwati di Pondok Perantren Darut Taqwa desa Ngembek Kecamatan Dlanggu Mojokerto.

Utari, 2007. Hubungan IMT dengan Tingkat Kesegaran Jasmani Usia 12-14 tahun. Thesis. Semarang : Universitas Diponegoro 